\section{O Porto e a construção da cidade moderna: $o$ caso do Hospital Geral de Santo António, nos séculos XVIII e XIX}

\section{Porto and the construction of the modern city: the case of Hospital Geral de Santo António in the eighteenth and nineteenth centuries}

\section{Helena da Silva}

Professora, Groupe de Recherche Identités et Cultures/ Université du Havre.

25 rue Philippe Lebon - BP 420

76600 - Le Havre - França

helena.rfdasilva@yahoo.com
SILVA, Helena da. O Porto e a construção da cidade moderna: o caso do Hospital Geral de Santo António, nos séculos XVIII e XIX. História, Ciências, Saúde Manguinhos, Rio de Janeiro, v.21, n.2, abr.-jun. 2014, p.709-725.

Resumo

Num período de crescimento demográfico e urbano da cidade do Porto, surgiu a necessidade de construir um novo hospital. A Santa Casa da Misericórdia do Porto, encarregue de erigir o novo estabelecimento de saúde, escolheu o arquiteto britânico John Carr para desenhar o projeto. Por meio da análise de um conjunto de fontes arquivísticas e de bibliografia diversa sobre o tema, examinamos os critérios escolhidos para a conceção e construção do Hospital Geral de Santo António e se este correspondeu às expetativas, tornando-se um espaço particular na cidade do Porto. Este artigo abre assim uma nova perspetiva sobre o estudo do desenvolvimento da cidade e da criação desse estabelecimento de saúde, contribuindo para a historicidade da arquitetura hospitalar.

Palavras-chave: arquitetura hospitalar; Santa Casa da Misericórdia do Porto; Portugal; higiene; cuidados de saúde.

\section{Abstract}

During a period of demographic and urban growth of the city of Porto, the need arose for a new hospital. The Santa Casa da Misericórdia of Porto, in charge of erecting the new health facility, appointed the British architect John Carr to design the project. By means of the analysis of a set of archival sources and sundry literature on the topic, we examine the criteria chosen for the design and construction of Hospital Geral de Santo António and if it fulfilled expectations, becoming a special space in the city. This article opens up a perspective on the study of the development of the city and the creation of this health facility, contributing to the historical trajectory of hospital architecture.

Keywords: hospital architecture; Santa Casa da Misericórdia of Porto; Portugal; hygiene; health care. 
A o longo dos séculos, na Europa ocidental, diversas ordens religiosas e irmandades desenvolveram um papel preponderante na assistência aos pobres e aos doentes, muitas delas em seus próprios estabelecimentos hospitalares, espaços particulares e essenciais da cultura urbana. Segundo a tradição cristã que regia essas confrarias, o doente era visto como Cristo em sofrimento; por isso, cuidar de um doente equivalia a libertar Cristo de sua dor. Nesse sentido, os cuidados do corpo eram concebidos em função dos cuidados espirituais para assim obter a salvação das almas.

O estudo do historiador Jacques le Goff sobre a cidade medieval francesa revela a importância das ordens mendicantes no centro da urbe, tentando responder aos problemas dos seus habitantes. Essas ordens romperam com a tradição de se isolar nos mosteiros, por meio da criação de conventos nas cidades para estarem mais próximas dos homens. Com o crescimento da cidade medieval, aumentou também o número de pobres, centro das atenções das ordens mendicantes que criaram redes urbanas de assistência aos necessitados. Num período em que a pobreza estava lado a lado com a doença, as ordens mendicantes fundaram também hospitais de reduzida dimensão, para receber os enfermos, alimentá-los e "curá-los", dentro dos limites técnicos e científicos da época medieval (Le Goff, 1980, p.234-237).

Na passagem da cidade medieval para a cidade moderna, a caridade para com os necessitados continuou a ser de grande importância para diferentes confrarias. Em Portugal, a Santa Casa da Misericórdia desempenhou desde o século XVI importante papel nos estabelecimentos hospitalares, inclusive na cidade do Porto. Num período de crescimento e de desenvolvimento urbano, tornara-se necessário construir um espaço específico para tratamento dos doentes.

Pretendemos conhecer como se constituiu e se consolidou esse espaço. Quais os critérios e exigências que levaram à construção do Hospital Geral de Santo António, no Porto moderno? No contexto de desenvolvimento dos tratamentos aos doentes característico dos finais do século XIX, esse estabelecimento hospitalar era a "máquina de curar" desejada pelos médicos? ${ }^{1}$

Para responder às questões colocadas, recorremos a uma metodologia histórica, nomeadamente ao levantamento de um conjunto de documentos existentes no Arquivo Histórico da Santa Casa da Misericórdia do Porto, incluindo a correspondência e os pagamentos relativos à construção do hospital, bem como os planos de construção elaborados pelo arquiteto britânico John Carr (1723-1807). Baseamo-nos ainda na literatura da época relativa à cidade do Porto, à construção do hospital em estudo e à arquitetura hospitalar noutros países europeus. Por último, desenvolvemos a leitura de bibliografia recente relacionada com o tema em análise.

\section{Uma urbe em mutação}

O Porto é conhecido internacionalmente pelo famoso "vinho do Porto", e o comércio dessa bebida foi, sem dúvida, a principal atividade da cidade durante o século XVIII. Essa atividade atraiu mercadores de toda a Europa, como ingleses, franceses, holandeses, dinamarqueses, suecos, entre outros, para a cidade (Costa, 1789, p.45). O comércio do vinho se beneficiou da instituição da Companhia Geral da Agricultura das Vinhas do Alto Douro, em 1756, pelo secretário de Estado Sebastião José de Carvalho e Melo, marquês de Pombal. Por sua vez, 
a cidade do Porto também saiu favorecida com a prosperidade desse comércio, que assim contribuiu para o desenvolvimento da urbe.

Devido à sua localização estratégica, nas margens do rio Douro e relativamente próxima da barra, a cidade escoava todos os produtos da região norte de Portugal. Assim, pela alfândega do Porto passavam variados produtos, destinados à exportação, como o linho, panos, louças, sumagre (planta utilizada na tinturaria e no curtimento de peles), frutas (laranjas, limões, castanhas), azeite, cortiça e vinho. As importações eram também em grande número, nomeadamente para responder aos pedidos de uma burguesia enriquecida com o comércio do vinho do Porto. Entre os produtos importados é de referir o açúcar, algodão, bacalhau, madeiras, couros, queijos, luvas, relógios, entre outros (Costa, 1789, p.47, 200-229).

O comércio, contudo, não era a única atividade da cidade; existiam também várias fábricas de produtos ligados ao vestuário (seda, meias, botões, panos de lã, chitas, gangas, toalhas, chapéus), ao vinho e a produtos domésticos (pipas, caldeiras, tachos, bacias, loiças, papel e vidro). A indústria mais importante, com cerca de trezentos trabalhadores, era a de cordas e massames, fundamentais para a construção naval e reparação dos navios que atracavam no porto (Costa, 1789, p.231-234).

Na segunda metade do século XVIII, a cidade do Porto era uma urbe em crescimento, em parte graças às suas atividades comerciais lucrativas. Ao descrever a cidade em 1789, Agostinho Rebelo da Costa menciona "aumento prodigioso" e que a população total em 1787 seria de 63.505 indivíduos (32.370 homens e 31.135 mulheres). Esse autor apresenta ainda outros dados, de estudos realizados anteriormente, para comprovar o aumento da população. Segundo dom Rodrigo da Cunha, em 1622, a população da cidade do Porto contava com 14.581 indivíduos; em 1732, o geógrafo Luís Cartano de Lima aumentava esse número para 20.737, e em 1772, Guilherme Guthrie mencionava já cinquenta mil pessoas na cidade do Porto (Costa, 1789, p.45). Esses dados significariam que a população da cidade triplicara em pouco mais de trinta anos, o que talvez seja um pouco exagerado. Agostinho Rebelo da Costa justifica esse crescimento pelo aumento do comércio e pela deslocação de um grande número de pessoas da região de Lisboa, depois do terramoto de 1755.

Hoje podemo-nos questionar se esses números são credíveis, sobretudo num período em que não havia ainda recenseamentos gerais da população (em Portugal, o primeiro data de 1864) e também porque desconhecemos quais os métodos estatísticos utilizados por Agostinho Rebelo da Costa. O autor declarou ter realizado um "laborioso exame" e não ter analisado os cadernos paroquiais, uma vez que os considerava incompletos, pois não contabilizavam a totalidade da população; não estavam registrados religiosos e religiosas, crianças com idade inferior a sete anos e pessoas que não professavam a religião católica (Costa, 1789, p.47). Com o desenvolvimento dos arrabaldes, é muito provável que o autor os tenha contabilizado, quando anteriormente essas freguesias não eram incluídas nas contagens da população da cidade.

Outros autores declararam que a população da cidade do Porto terá duplicado ao longo do século XVIII, principalmente nas décadas de 1760 e 1770 (Silva, 2001, p.20). Mesmo sem dados precisos, podemos considerar que o Porto estava em plena expansão, com a construção de novas casas, edifícios públicos e ruas (Costa, 1789, p.46). Já o autor desconhecido do Compêndio histórico e topográfico da cidade do Porto mencionou a construção, entre 1770 e 1804, de 27 novas ruas ao longo de vários quilómetros, o alargamento de outras artérias da 
cidade, a construção de praças, largos e espaços verdes. ${ }^{2}$ Esse crescimento fez-se em parte fora dos muros da antiga urbe, levando assim à destruição de uma parte da muralha fernandina, construída no século XIV (Figura 1).

Essa passagem da cidade medieval, fechada em suas próprias muralhas, à cidade moderna, ficou a dever-se a um vasto projeto de transformação urbana da parte dos Almadas, na segunda metade do século XVIII e inícios do século XIX. João de Almada e Melo (1703-1786), ${ }^{3}$ primo direto do marquês de Pombal, iniciou essa reorganização da cidade, e o filho Francisco de Almada e Mendonça (1757-1804) ${ }^{4}$ continuou seu plano de modernização, incluindo variadas obras com vista a melhorar a circulação do centro para fora da cidade (a partir da criação de eixos estratégicos em direção ao norte, nordeste, leste e sul) e também no interior da cidade (abertura de novas ruas, como já citamos, e o alinhamento de outras através da regularização das fachadas dos edifícios).

Os novos arruamentos contrastavam com as ruelas do burgo intramuros, tipicamente sombrias, úmidas e tortuosas. Verificamos que existe na obra dos Almadas preocupação crescente para as questões de higiene, ligada à importância da circulação do ar. Assim criaram também espaços verdes com vista para o rio Douro, como alamedas e praças, que eram locais de passeio para a burguesia enriquecida que se instalara nas novas ruas. Podemos aqui verificar certa influência inglesa, numa cidade em que essa comunidade era numerosa; não podemos esquecer que os Almadas tinham relações próximas com o cônsul britânico John Whitehead (1726-1802) (Taylor, 1960, p.15).

Os Almadas foram também responsáveis pela criação de diversos equipamentos coletivos do Porto, como o Tribunal e a Cadeia da Relação, o Quartel-general, a Casa Pia, a Academia Politécnica e o Teatro São João. Muitas dessas obras foram realizadas num curto espaço de tempo graças às taxas camarárias impostas sobre o comércio do vinho do Porto, que assim contribuíram para a modernização da cidade (Gonçalves, 2006, p.47).

\section{Caridade na cidade do Porto}

Seguindo a tradição medieval e a crença de que a salvação da alma seria obtida por meio da esmola ao pobre, constatamos a existência de diversas ordens ou irmandades que se ocupavam da caridade na cidade do Porto. Elas utilizavam as doações de capital de uma parte da população portuense, relativamente enriquecida graças ao comércio e à pequena indústria, para assistir os necessitados. Quanto aos habitantes do Porto, "a caridade é a que mais os domina", pois respeitando as características de um "verdadeiro cristão" inúmeras casas distribuíam esmola às famílias mais pobres. Na cidade existiam então 15 estabelecimentos hospitalares (Costa, 1789, p.51).

Um deles era da Ordem Terceira de São Francisco, situado intramuros, seguindo a ideia apresentada pelo historiador francês Jacques Le Goff sobre as ordens mendicantes e a construção de conventos (e hospitais) nas cidades medievais. Esse edifício foi descrito como "um sumptuoso hospital, aonde se tratam com exemplar caridade, e decência os Irmãos enfermos; e independentemente deste uma grande enfermaria em que habitam continuamente vinte e seis Irmãos entrevados" (Costa, 1789, p.107). Essa citação revela bem que o hospital 


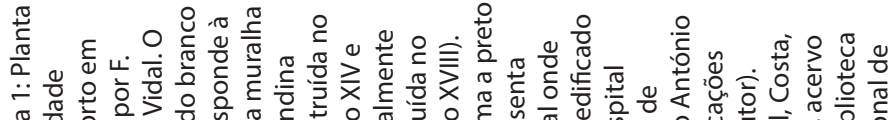

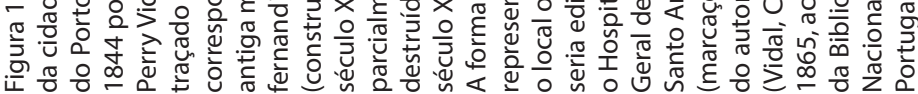

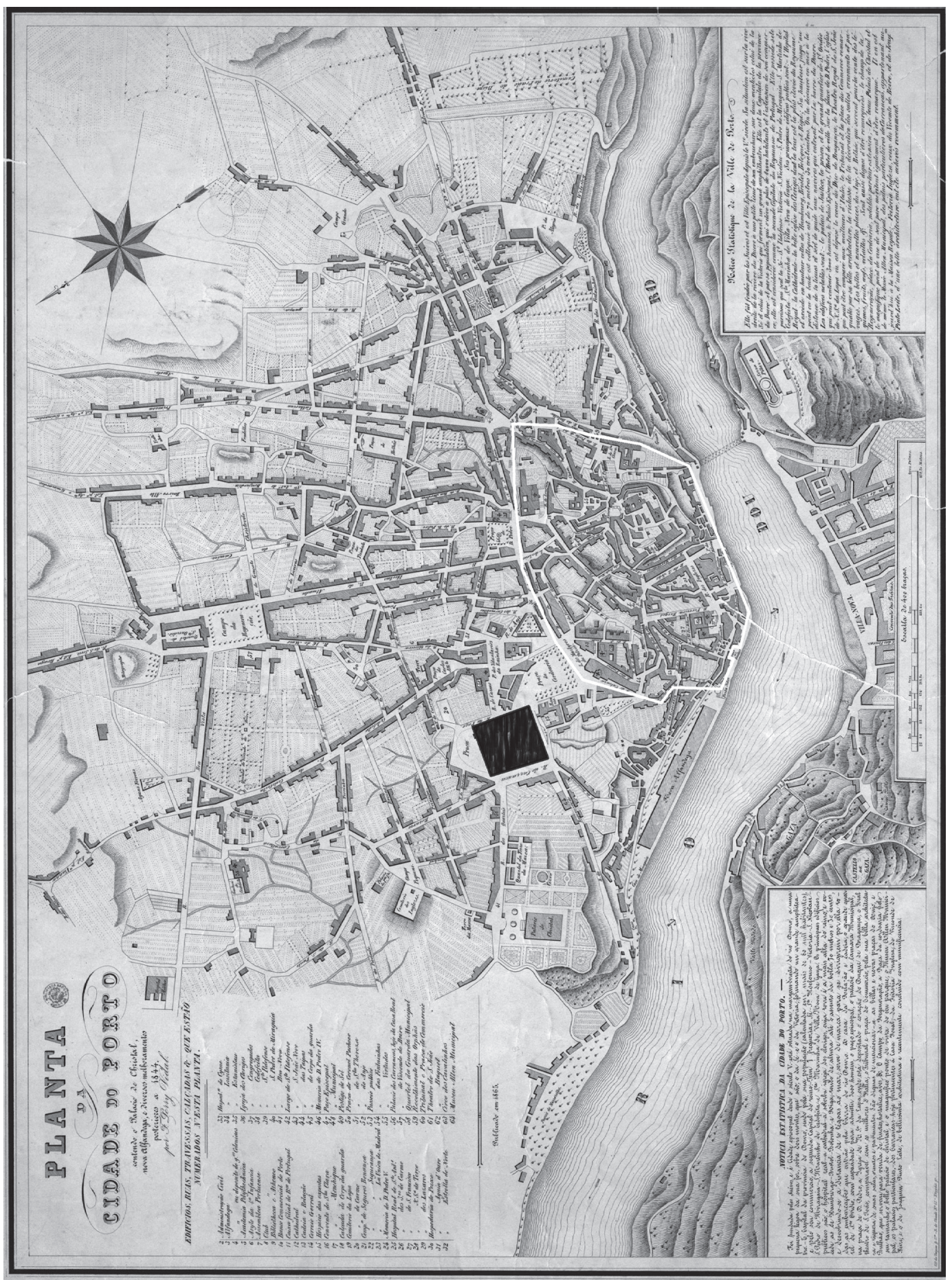


não tinha como única função o restabelecimento da saúde, uma vez que albergava aqueles que eram incapazes de trabalhar e de assegurar um meio de subsistência.

Rebelo da Costa referiu que a Irmandade de Nossa Senhora do Terço e da Caridade tinha "um bom hospital" 5 e mencionou brevemente os hospitais de São Crispim, das Mulheres Pobres, dos Ingleses, da Senhora da Silva e dos Clérigos. Mas o autor concentrou-se sobretudo nos hospitais da Santa Casa da Misericórdia do Porto. ${ }^{6}$ Segundo ele, em 1787, essa confraria cuidava de mais de dois mil enfermos por ano e administrava oito estabelecimentos hospitalares: o Hospital Real, dos Expostos, dos Presos, dos Entrevados, das Entrevadas, dos Lázaros, das Lázaras e das Velhas (Costa, 1789, p.98, 124). Como indicam os nomes dos hospitais, a maioria era albergarias que acolhiam e sustentavam crianças abandonadas (expostos), inválidos (entrevados, entrevadas e velhas), leprosos (lázaros e lázaras) e presos (possivelmente doentes). Esses hospitais-albergarias teriam reduzida capacidade, sendo de dimensão semelhante à de uma casa. Apenas o Hospital Real (ou Dom Lopo ${ }^{7}$ ) se aproximava de um hospital, no sentido atual, mesmo sendo os cuidados de saúde ainda limitados. Destacava-se pela sua grandeza e pelo elevado número de doentes que recebia, certamente em comparação com os outros estabelecimentos da cidade do Porto (Costa, 1789, p.125).

O Hospital Dom Lopo, localizado numa das principais ruas da urbe intramuros (rua das Flores), resultava de um conjunto de obras de ampliação do Hospital Rocamador, ${ }^{8}$ nomeadamente da aquisição de casas e quintas da vizinhança. No século XVII, o Hospital Dom Lopo era constituído por duas enfermarias (uma com 42 camas para mulheres, e a outra com 38 camas para homens), altares e capelas para que os doentes pudessem ouvir a missa, e um claustro com uma fonte para abastecer de água o hospital (Sousa, abr. 1993, p.98-106; Basto, 1998, p.21-26).

Rapidamente esse estabelecimento revelou-se insuficiente para responder ao crescente número de doentes que a ele acorriam. Em 1766, julgou-se inconveniente tentar efetuar obras de alargamento no Hospital Dom Lopo, por uma questão económica, pois isso implicaria a compra dos prédios vizinhos e também por uma questão de higiene (Silva, 1998, p.22-23). O hospital estava no centro da cidade, junto do cemitério, o que na época não era considerado benéfico para o tratamento dos enfermos, seguindo a teoria aerista de que o ar estaria corrompido e seria propício para o contágio de epidemias. Assim, o provedor da Santa Casa, dom António de Lencastre, decidiu iniciar a construção de um novo hospital.

\section{O hospital monumento}

Numa cidade em crescimento, tornara-se fundamental melhorar os cuidados de saúde dos doentes cujo número aumentava progressivamente. A Santa Casa procurava criar um hospital que acompanhasse o crescimento da urbe, e pediu autorização ao monarca português para erigir um novo estabelecimento de saúde, no sítio de São Lázaro, fora das muralhas.

A 12 de junho de 1767, o rei dom José I (1714-1777) autorizou a construção do novo hospital, concordando com a escolha do local, pois os terrenos eram "de ares mais benignos e saudáveis" e que tal infraestrutura seria benéfica para os doentes e para a cidade do Porto (Dom José, 12 jun. 1767). Essa afirmação relembra novamente a importância do "ar puro", segundo as teorias aeristas. 
Contudo, na carta de 3 de junho de 1768, o rei afirma que São Lázaro não seria o local ideal porque não haveria água suficiente para o hospital e que o lugar era "um pouco distante". ${ }^{9}$ O rei dom José I (3 jun. 1768) autorizou então a construção do hospital num terreno "fora das portas" da cidade porque tinha "ares puros, e saudáveis" e porque se poderia utilizar a mesma água do Hospital Dom Lopo, havendo ainda um outro curso de água próximo (o rio Frio ou rio das Virtudes). Assim podemos considerar que o local para a construção do novo hospital foi escolhido em função das teorias higienistas da época, pois a qualidade do ar e da água era fundamental. Era também essencial que o hospital ficasse fora das antigas muralhas, acompanhando o crescimento da cidade (Figura 1).

Nessa carta, dom José estabelece ainda que a construção seria supervisionada por João de Almada e Melo, como as restantes obras públicas do Porto. Como já referimos, este era próximo do cônsul britânico John Whitehead, o que certamente interferiu na escolha de John Carr como arquiteto do futuro hospital, uma vez que eram amigos de infância. Paralelamente, o capelão da comunidade britânica, Henry Wood, teria também ajudado nessa decisão, pois é referido na correspondência trocada entre John Carr e a Misericórdia. O facto de contratar um arquiteto britânico foi considerado inovador, porque, tradicionalmente, na cidade do Porto os arquitetos eram franceses, espanhóis ou da península itálica. Podemos ainda acrescentar que João de Almada tornar-se-ia provedor da Santa Casa da Misericórdia do Porto em 1772, sucedendo a dom António de Lencastre, que tinha sido nomeado governador e capitão-geral de Angola (Dom José, 22 jun. 1772).

John Carr era originário de uma família de pedreiros, de Horbury (Reino Unido), com quem muito jovem começou a trabalhar. Com a construção do Kirby Hall (1747-1755, Yorkshire) tornou-se arquiteto reconhecido no norte da Inglaterra, conseguindo diversos pedidos de construção de casas e edifícios públicos, e passando a ser considerado um dos principais arquitetos de Yorkshire (Taylor, 1960, p.14-15). Relativamente à construção de estabelecimentos de saúde, na sua carta de 5 de novembro de 1769, John Carr declarou que estava "erguendo um grande hospital para doenças várias" aludindo provavelmente à General Infirmary de Leeds, construída entre 1768 e 1771 (e projetada por Carr). Acrescentou que era a pessoa que mais "Hospitais e Edifícios Grandiosos" tinha construído em Inglaterra e anunciou ter efetuado "uma viagem por este reino [Reino Unido] para ver os seus principais hospitais antes de iniciar a planta" (citado em Alves, 1988, p.140). Infelizmente John Carr não mencionou os hospitais que visitou nem sua opinião sobre as construções hospitalares existentes no Reino Unido nesse período. De referir que alguns anos depois de elaborar o projeto do Hospital Geral de Santo António, Carr projetou outros dois hospitais britânicos: York County Lunatic Asylum (1774-1777) ${ }^{10}$ e Lincoln County Hospital (1776-1777).

Segundo René Taylor (1960, p.19), a Misericórdia pediu ao arquiteto um hospital "com a grandeza e comodidade para que nele se acomodasse tudo o que respeitava a doenças e Medicina". Na carta que Carr enviou ao provedor da Misericórdia a 7 de agosto de 1769 ele declarou ter elaborado o projeto segundo o que lhe tinha sido pedido, mas acrescentou que, quando recebeu as últimas instruções, já tinha completado o plano, não dando mais detalhes. Desconhecemos se a Misericórdia fez novos pedidos ou outras exigências. Também não sabemos se John Carr chegou a visitar o Porto e o local onde seria construído o hospital ou se se baseou apenas em informações dadas pelo provedor da Misericórdia. 
John Carr mencionou ainda na mesma carta que esse projeto tinha chamado a atenção do rei de Inglaterra, que exigiu ver os planos, "com admiração e aprovação". ${ }^{11}$ Com essa afirmação sabemos que a construção do novo hospital do Porto era tema de conversa em Inglaterra, talvez devido à grandiosidade do projeto. Apercebemo-nos também da importância do arquiteto John Carr em seu país, uma vez que tinha contactos com o monarca, a quem mostrou o projeto que tinha concebido para o novo hospital.

Pelo "extenso plano", John Carr pediu o pagamento de quinhentas libras, que considerava "recompensa muito moderada" se comparada com o que exigia habitualmente em Inglaterra, mas como esperava ver uma parte da obra erigida não exigia soma mais elevada (Carr, 7 ago. 1769). Por essa afirmação, o arquiteto parecia estar consciente dos recursos limitados que possuía a Santa Casa para construir tal edifício e pressagiar as dificuldades económicas que se fariam sentir para concluir a obra.

O projeto, incluindo a planta completa, a descrição geral e a explicação pormenorizada das salas, foi enviado por via marítima, por intermédio do capitão Robert Schonswar, que regressaria ao Reino Unido com o pagamento de quinhentas libras (Carr, 10 ago. 1769). Na planta desenhada por John Carr estava prevista a construção de um hospital de forma quadrangular, com um grande quase quadrado de 178 metros (nos lados norte e sul) por 172 metros (nos lados nascente e poente). Ao centro do enorme pátio interior, Carr projetou uma igreja, com planta em cruz grega e zimbório de cerca de 44 metros de altura.

Esse projeto hospitalar de forma quadrangular não era original; pelo contrário, seguia o modelo tradicional do hospital, organizado como residência e construído à volta de pátio interior. Ao longo do século XVIII, vários hospitais foram construídos ou modificados segundo esse modelo, nomeadamente no Reino Unido, como, por exemplo, o Guy's Hospital, em Londres (1722-1725), o Royal Naval Hospital, em Haslar (1746-1761), e o Royal Naval Hospital, em Plymouth (1758-1762) (Forty, 1980; Richardson, Goodall, 1998; Stevenson, 2000).

Carr desenhou o hospital segundo o estilo neopalladiano, muito utilizado no Reino Unido, especialmente para a construção de casas de campo de aristocratas, bem como de edifícios públicos incluindo hospitais, como os mencionados, por exemplo. O Hospital Geral de Santo António tinha assim estrutura simétrica, sendo as alas nascente e poente iguais entre elas, mas diferentes das alas perpendiculares, norte e sul, que eram simétricas entre si. As fachadas do edifício seriam decoradas com frontões, balaustradas, colunatas e pórticos. Seria um espaço monumental, quer a parte exterior, quer a interior, virada para o pátio (Costa, 1789, p.126-127; Alves, 1988, p.141-142).

Há, contudo, uma diferença relativamente à utilização de materiais. No Reino Unido, o tijolo era o material por excelência utilizado nas construções, enquanto na cidade do Porto esse era o granito. Assim, o novo hospital foi construído em granito, como outros grandes edifícios dessa urbe. Sobre esse assunto, algumas referências indicam que Carr projetou o edifício para ser construído em tijolo e que teria ficado "muito surpreendido quando soube que [as paredes] eram feitas de granito" (Rodrigues, 1 nov. 1884, p.246).

Convém acrescentar que esse projeto tinha uma planta corredor, ou seja, a circulação fazia-se pelos corredores interiores do edifício, contrastando com a planta pavilhão, em que a circulação era feita pelo exterior. Nesse aspeto, John Carr terá certamente seguido o exemplo do Royal Naval Hospital, de Haslar, projetado por Theodore Jacobsen (Oppert, 1867, p.10-13; 
Providência, 2000, p.35). Desconhecemos, contudo, por que Carr optou por esse modelo mais clássico, sendo que poderia ter escolhido o modelo contemporâneo do hospital de Plymouth (planta pavilhão), que se tornaria exemplo a seguir nas décadas seguintes.

Relativamente à distribuição do espaço interior, como numa mansão palladiana ou noutros hospitais britânicos, os espaços públicos eram os mais próximos das entradas (piso térreo), e os espaços mais privados e restritos estavam reservados aos pisos superiores (Forty, 1980, p.69-70). Assim, para o piso térreo do Hospital Geral de Santo António, John Carr projetou as salas de receção dos doentes e dos enjeitados, as salas para tratamento dos pacientes não hospitalizados e ainda outra sala em que os médicos, cirurgiões e boticários faziam suas juntas (ou consultas). Nesse piso estavam também projetados diversos serviços essenciais ao bom funcionamento do hospital, tais como cozinhas, lavandarias e aposentos para o pessoal (criados, cozinheiros, estudantes de medicina, boticário, sacristão), bem como três enfermarias para doentes do foro psiquiátrico.

O segundo piso seria ocupado pelas diversas enfermarias, havendo divisão segundo a patologia dos pacientes. Assim o lado norte seria para as enfermarias das "febres"; o lado poente para leprosos, feridos e doentes particulares; o lado sul para doenças venéreas e doentes entrevados; e o lado nascente para doentes tuberculosos e particulares. Nesse piso haveria ainda um conjunto de serviços, nomeadamente alojamentos, salas de visitas e ainda quatro salas com cisternas para abastecer de água o andar. Carr tinha ainda previsto a construção no lado poente de balcões ou varandas em que os doentes pudessem passear e "gozar do ar". O terceiro piso, espaço mais privado e restrito, acolheria os enjeitados e as suas amas (Alves, 1988, p.143-146).

Segundo Agostinho Rebelo da Costa (1789, p.127), o projeto dessa "grande máquina" constava de 20.609 portas e janelas, 159 salas e salões, 142 enfermarias públicas e 97 privadas. O projeto desenhado por John Carr apresentava várias soluções para responder às exigências higiénicas da época, destacando-se a preocupação com ventilação, abastecimento de água e saneamento. Relativamente à circulação do ar, estava prevista a colocação de ventiladores em todas as enfermarias e de um sistema de tubagens até ao telhado para assim "ter uma corrente perpétua de Ar, e evacuar o Ar corruto das Enfermarias". Em todo o edifício existiria uma divisória interna, invisível do exterior, que contribuiria para a renovação do ar e onde seriam colocados os sanitários. Cada piso teria uma reserva individual de água com bombas para que esta chegasse às partes mais altas do edifício. Existia também uma galeria subterrânea, onde haveria "uma corrente perpétua d'água" e todo o sistema coletor de saneamento. Contra um possível incêndio no hospital e para reforçar a estrutura do edifício, John Carr projetou, no primeiro piso, tetos "arqueados, ou abóbadas", e no subsolo uma galeria em que corria permanentemente água (o rio Frio ou o rio das Virtudes), que poderia também ser utilizada para controlar o fogo. Ao longo de todo o edifício existia também um grande corredor de acesso ao pátio central, que permitia proteger as enfermarias de exposição direta ao sol (Taylor, 1960, p.20-21, p.28; Providência, 2000, p.33-34).

Apesar de o projeto exceder o orçamento da Santa Casa da Misericórdia do Porto, as obras iniciaram em 15 de julho de 1770. Nessa data lançou-se a primeira pedra, numa cerimónia repleta de simbolismo e de religiosidade, que incluiu uma procissão da igreja da Misericórdia até ao local onde seria erigido o futuro estabelecimento hospitalar. ${ }^{12}$ Vários foram os entraves à construção do Hospital Geral de Santo António, ${ }^{13}$ que contribuíram para aumentar os 
custos inicialmente previstos e que obrigaram a parar as obras em diversas ocasiões. Surgiram problemas inerentes à construção, como a necessidade de nivelar o terreno, de construir alicerces profundos e muros de suporte de grande espessura, mas também relacionados com a demissão de vários técnicos e responsáveis pelas obras, devido à introdução abusiva de modificações ao projeto inicialmente traçado por John Carr (Silva, 2010, p.114-115).

A falta de capital levou também à paragem da construção em vários momentos, tendo mesmo sido criadas lotarias por diferentes monarcas portugueses com vista a aplicar os lucros nas obras (Alves, 1988, p.150-155; Taylor, 1960, p.22-25). Nas palavras de Agostinho Rebelo da Costa $(1789$, p.128), "esta imensa fábrica, que como disse, está ainda nos seus princípios, não poderá concluir-se com a brevidade necessária, sem que um grande socorro de dinheiro a auxilie". Por último, os conflitos militares que se verificaram no território portuense (as invasões francesas entre 1807 e 1811 e a guerra civil entre 1832 e 1834) e as suas consequên-cias económicas, sociais e sanitárias retardaram o avanço das obras (Sousa, maio 1993, p.130-135).

Com o Hospital Dom Lopo sobrelotado, os primeiros doentes chegaram ao novo hospital a 19 de agosto de 1799, quando as obras ainda decorriam (Serrano Júnior, 1980, p. 7-8). O projeto inicial de Carr foi modificado várias vezes e nunca chegou a ser concluído. Pouco menos de metade do grande quase quadrado foi construído, pois dos quatro pórticos projetados, apenas um foi edificado (Figuras 2 e 3). Assim, apenas a fachada do lado nascente foi terminada, bem como uma parte das fachadas dos lados norte e sul, ficando por erigir todo o lado poente e a igreja (Figuras 4 a 6). Não obstante, esse estabelecimento hospitalar tornou-se o maior hospital do Porto, e um espaço particular para o tratamento dos doentes nessa cidade durante longas décadas, sempre administrado pela Irmandade da Santa Casa.

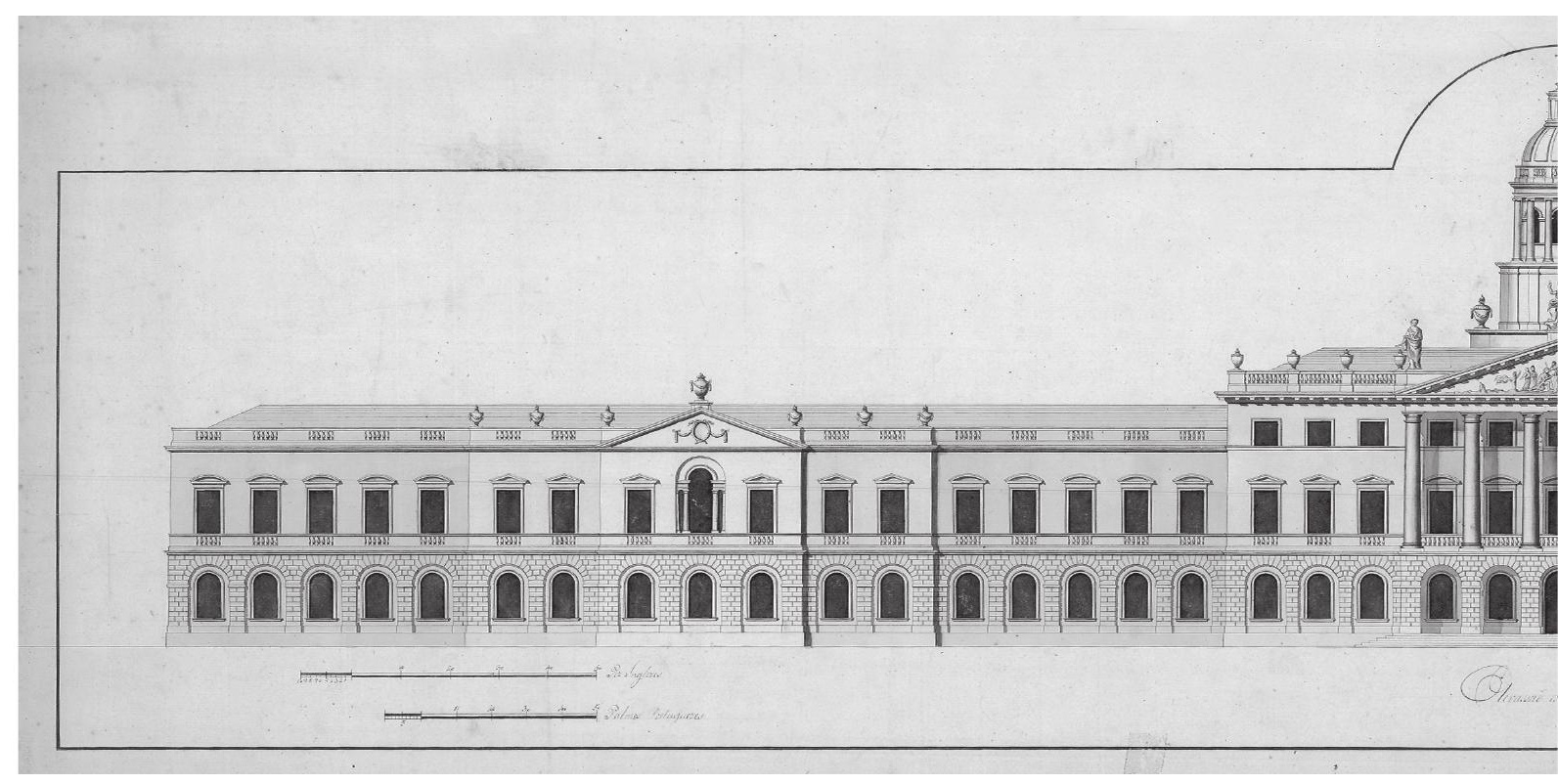

Figura 2: Uma das fachadas projetadas por John Carr para o Hospital Geral de Santo António. No centro da figura encontra-se o zimbório de 44 metros da igreja que nunca foi erigida. (Alçado original do Hospital de Santo António, Arquivo Histórico da Santa Casa da Misericórdia do Porto) 
das camas, das salas e dos pavilhões para acelerar o tratamento dos doentes (Tenon, 1788, p.ix-xii, p.344-350, p.384-394).

Como vimos, o arquiteto britânico John Carr tinha planeado a construção de sistemas de ventilação, de abastecimento de água e de esgotos, tinha definido claramente os espaços, separando as enfermarias segundo as patologias e tinha também pensado nos pacientes projetando varandas em que eles poderiam apanhar ar e um jardim no pátio interior para poderem passear. Contudo, a prolongação das obras no decorrer de várias décadas e a falta de capital levaram a modificar os planos iniciais, sendo que muitas dessas medidas nunca chegaram a ser implementadas, dando origem a diversas críticas sobre a falta de condições de higiene no hospital.

Por exemplo, em 1865, João Mendes Osório, mesário da Misericórdia do Porto, chamou a atenção dos restantes membros da mesa para um conjunto de defeitos do edifício do Hospital Geral de Santo António. Segundo ele, as enfermarias, de dimensões reduzidas e muito sombrias, caracterizavam-se por "falta quase absoluta de higiene" que horrorizava quem ali entrava. Esse mesário chegou mesmo a propor a construção de um novo hospital (Osório, 1868, p.30-32), o que foi também defendido por outras personalidades da cidade do Porto. Para o doutor Pedro Ferreira (1833-1913), abade de Miragaia, a localização do hospital tinha sido incorretamente escolhida porque ele estava erigido sobre um curso de água, num terreno pantanoso e úmido, o que obrigou à construção de uma galeria abobadada subterrânea e de alicerces consequentes (Silva, 2008, p.184). Esse mesmo facto foi argumento diversas vezes utilizado para criticar a escolha do local em que o hospital foi construído (Rodrigues, 11 nov. 1884, p.253-254).

Costa Simões (1883, p.400) criticou a monumentalidade do edifício, mas também suas condições higiénicas. Segundo esse médico, a iluminação e a ventilação eram deficientes, referindo que faltava "o ar preciso para tão grande número de doentes". Assim, insistiu que o hospital estava sobrelotado, pois defendia que cada doente deveria ter um espaço de $60 \mathrm{~m}^{2}$

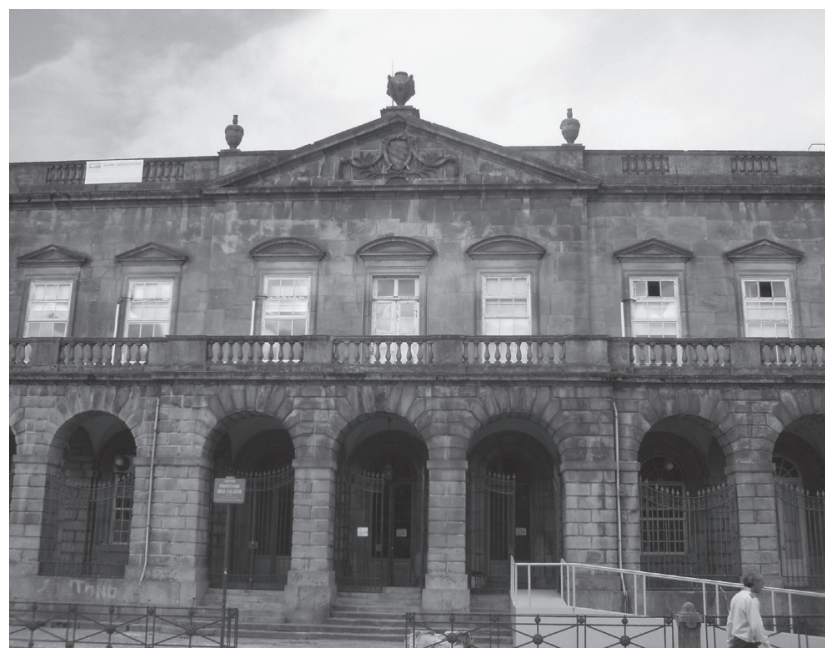

Figura 5: Pormenor da fachada nascente do Hospital Geral de Santo António (fotografia da autora, junho 2007)

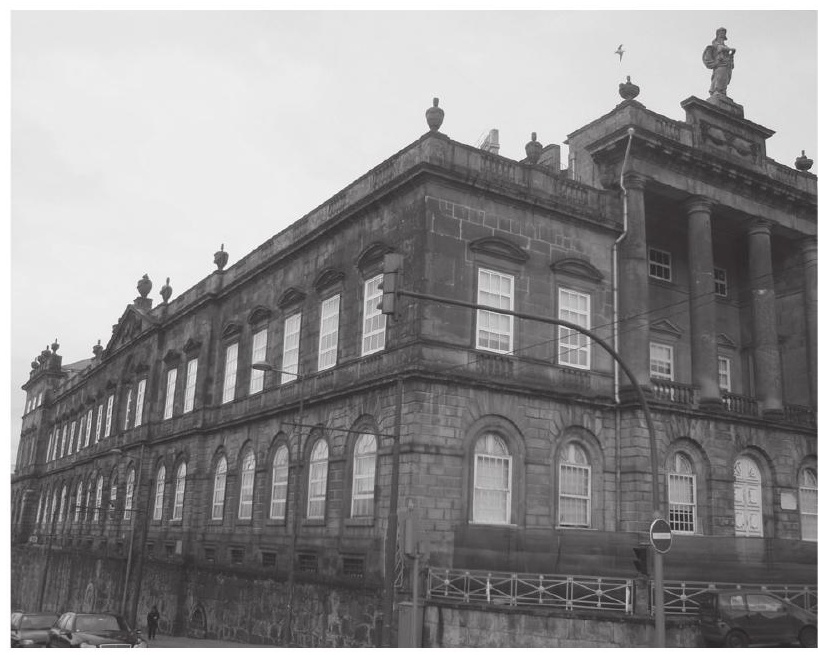

Figura 6: Fachada Sul e parte da nascente do Hospital Geral de Santo António (fotografia da autora, dezembro 2010) 
e que, segundo esse cálculo, o edifício deveria ter apenas 404 camas, mas tinha 719, ou seja, quase o dobro. Costa Simões apresentou um projeto detalhado para a construção de um novo estabelecimento hospitalar, constituído por um conjunto de pavilhões, e seguindo o sistema de Casimir Tollet $(1894,1889)$ quanto aos materiais de construção, ventilação, aquecimento e esgotos. Costa Simões defendia que o Hospital Geral de Santo António era um "ótimo edifício para muitas repartições públicas e péssima casa para um hospital, como deverá ser o da misericórdia do Porto" (Simões, 1883, p.xxix-xxxiii).

Apesar dessas opiniões, o Hospital Geral de Santo António era o principal estabelecimento de saúde portuense e, sem dúvida, um espaço singular para o tratamento dos doentes e o restabelecimento da saúde na cidade do Porto, característica que manteve até aos nossos dias.

\section{Considerações finais}

Esta análise demonstrou que no século XVIII, a cidade do Porto conheceu um momento de prosperidade que correspondeu também a um desenvolvimento urbanístico, muito graças ao crescimento do comércio do vinho do Porto e à ação dos Almadas. Assim, a cidade ultrapassou os limites da antiga muralha medieval, novas ruas foram abertas, novos espaços verdes foram criados, e novas estruturas coletivas foram edificadas, construindo-se uma cidade moderna.

No mesmo momento, a Misericórdia do Porto, que continuava a ocupar papel primordial na assistência aos pobres e aos doentes, desejava ter um novo hospital. Embora com recursos financeiros limitados, essa irmandade pretendia construir um grande estabelecimento em que os doentes pudessem não apenas ser acolhidos e albergados mas também tratados de forma a recuperar rapidamente a sua saúde. John Carr desenhou um hospital em forma quadrangular e de estilo neopalladiano, o que era então uma novidade na cidade do Porto, dominada pelo estilo barroco. Apesar de o projeto ter sido bastante modificado e ter ficado incompleto, definiu o estilo neoclássico que marcou as construções arquitetónicas do Porto moderno, e que se distinguem do resto do país. Vários edifícios civis de grandes dimensões foram depois edificados na cidade, inspirados na fachada do novo hospital e no seu estilo neopalladiano inglês, tais como a Feitoria Inglesa, o Palácio da Bolsa, a Real Academia de Marinha e Comércio (hoje o edifício pertence à Universidade do Porto), e o Palácio dos Carrancas (hoje Museu Nacional Soares dos Reis). Convém ainda referir que vários engenheiros e arquitetos portugueses que colaboraram na construção do Hospital Geral de Santo António assinaram depois outros projetos arquitetónicos de relevo para a cidade. O projeto desse hospital abriu, portanto, uma nova era na construção arquitetónica, fundamental para a edificação do Porto moderno, e que ainda hoje caracteriza a cidade.

Quanto ao hospital em si, John Carr desenhou um estabelecimento segundo um conjunto de exigências higiénicas, essenciais para a época, como um bom sistema de ventilação, de abastecimento de água e de esgotos, a separação dos doentes segundo a patologia, e a existência de espaços em que eles pudessem arejar fora das enfermarias. Contudo, a monumentalidade do edifício, o atraso das obras, as alterações ao projeto e o facto de ele ficar inacabado originaram várias críticas, nomeadamente de alguns médicos que acusavam o Hospital Geral de Santo António de não responder às necessidades higiénicas. Esses médicos defendiam a construção 
de um novo hospital; entretanto, a Santa Casa da Misericórdia do Porto nunca avançou com nenhum dos projetos.

Ao longo do século XIX, as sucessivas administrações foram efetuando obras com vista a melhorar as instalações, nomeadamente em relação às condições de higiene das enfermarias e de conforto dos pacientes. O Hospital Geral de Santo António continuou a ser administrado pela Irmandade da Santa Casa (até à sua nacionalização em 1976) e, apesar de o projeto inicial nunca ter sido concluído, esse hospital continuou a ser o mais importante estabelecimento de saúde no Porto até à construção do Hospital de São João (em 1959) pelo Estado português. Já nos finais do século XX, o Estado construiu um novo edifício nos restantes terrenos do Hospital Geral de Santo António, aumentando a capacidade desse estabelecimento de saúde, que continua ainda hoje em funcionamento.

\section{NOTAS}

${ }^{1}$ A expressão machines à guérir foi utilizada por Michel Foucault, referindo-se a essa revolução na construção hospitalar e ao desejo de construir estabelecimentos de saúde com excelentes condições para permitirem bom tratamento e rápida recuperação dos doentes (Foucault et al., 1979).

${ }^{2} \mathrm{O}$ manuscrito Compêndio histórico e topográfico da cidade do Porto foi transcrito por Francisco Ribeiro da Silva (2001, p.149-151).

${ }^{3}$ Seguindo a tradição familiar, João de Almada e Melo iniciou sua carreira nas armas. Chegou ao Porto em 1757, aquando do motim que visava pôr fim à Companhia Geral da Agricultura das Vinhas do Alto Douro. Nesse mesmo ano, tornou-se governador de Armas do Porto e sete anos depois governador da Justiça e da Relação do Porto, acumulando assim os dois cargos mais importantes da cidade (Alves, 1988, p.19-37).

${ }^{4}$ Tendo estudado leis na Universidade de Coimbra, Francisco de Almada e Mendonça ocupou vários cargos na cidade do Porto, como corregedor e provedor, desembargador, juiz, deputado, inspetor das obras públicas, entre outros (Alves, 1988, p.39-45).

${ }^{5}$ Sobre esse estabelecimento leia-se Barreira (2006, p.109-118).

${ }^{6}$ Fundada em 1499 pelo rei dom Manuel (1495-1521), a Misericórdia do Porto tinha como objetivo assegurar assistência espiritual e corporal aos pobres, seguindo o modelo da Misericórdia de Lisboa. A partir de 1521 a Misericórdia do Porto administrou vários hospitais da cidade (Basto, 1997, p.200-230, 336).

${ }^{7}$ Nome escolhido em homenagem a dom Lopo de Almeida (1556-1598), cónego do rei dom Filipe II de Espanha, que legara sua fortuna aos pobres, sendo ela gerida pela Santa Casa da Misericórdia do Porto.

${ }^{8}$ As origens deste hospital estão provavelmente ligadas à Confraria de Rocamador, originária de França e presente em Portugal desde o século XIII (Sousa, abr. 1993, p.99-101).

${ }^{9}$ Alguns autores referem que um dos mesários morava na Cordoaria e que teria insistido para que o novo hospital fosse construído perto da sua residência (Rodrigues, 1 nov. 1884, p.244).

${ }^{10}$ Sobre esse hospital leia-se Digby (1986).

${ }^{11}$ Nessa e nas demais citações de textos em inglês, a tradução é livre.

${ }^{12}$ Sobre essa cerimónia leia-se Basto, 1998, p.30-33; Alves, 1988, p.147-149.

${ }^{13}$ Relativamente à escolha do nome desse novo estabelecimento, houve inicialmente votação dos 13 mesários da Misericórdia do Porto, mas, como quatro deles tinham o antropónimo António, decidiram proceder a uma tiragem à sorte entre os três nomes mais votados. António foi novamente selecionado.

${ }^{14}$ Costa Simões (1819-1903) estudou medicina na Universidade de Coimbra, onde mais tarde ensinou histologia e fisiologia. Durante 15 anos administrou os hospitais da Universidade de Coimbra, tendo sido também diretor técnico e económico do Hospital Geral de Santo António e um homem político (Soares, 2001, p.64-69). 


\section{REFERÊNCIAS}

AIKIN, John.

Thoughts on hospitals. London: Joseph Johnson. 1771.

ALVES, Joaquim Jaime B. Ferreira.

O Porto na época dos Almadas. Arquitectura. Obras públicas, v.1. Porto: Câmara Municipal do Porto. 1988.

BARREIRA, Aníbal.

A Irmandade de Nossa Senhora do Terço e Caridade da cidade do Porto: a construção do hospital. In: Departamento de Ciências e Técnicas do Patrimônio; Departamento de História (Org.). Estudos em homenagem ao Professor Doutor José Amadeu Coelho Dias. v.1. Porto: Faculdade de Letras da Universidade do Porto, p.109-118. 2006.

BASTO, A. de Magalhães.

Origens e desenvolvimento de um grande estabelecimento de assistência e caridade: o Hospital de Santo António da Misericórdia do Porto. Porto: Santa Casa da Misericórdia do Porto. 1998.

BASTO, A. de Magalhães.

História da Santa Casa da Misericórdia do Porto. V.1. Porto: Santa Casa da Misericórdia do Porto. 1997.

BIELFELD, Jakob Friedrich Freiherr von. Institutions politiques: par monsieur le baron de Bielfeld. V.1. Leyde: F. Bassompierre. 1768.

CARR, John.

Carta ao Cap. ${ }^{\mathrm{n}}$ Schonswarr. Hospital novo: cartas régias e títulos das compras. Seção D, banco 1, livro n.1. Documentos manuscritos (Arquivo Histórico da Santa Casa de Misericórdia do Porto, Porto). 10 ago. 1769.

CARR, John.

Carta. Hospital novo: cartas régias e títulos das compras. Seção D, banco 1, livro n.1. Documentos manuscritos (Arquivo Histórico da Santa Casa de Misericórdia do Porto, Porto). 7 ago. 1769.

COSTA, Agostinho Rebelo da.

Descripção topográfica, e histórica da cidade do Porto. Porto: Oficina de Antonio Alvarez Ribeiro. 1789.

DIGBY, Anne.

From York Lunatic Asylum to Bootham Park Hospital. York: University of York. 1986.

DOM JOSÉ.

Carta ao Provedor, Oficiais, e mais Irmãos da Mesa da Misericórdia da Cidade do Porto. Hospital novo: cartas régias e títulos das compras. Seção D, banco 1, livro n.1. Documentos manuscritos (Arquivo Histórico da
Santa Casa de Misericórdia do Porto, Porto). 22 jun. 1772.

DOM JOSÉ.

Carta ao Provedor, Oficiais, e mais Irmãos da Mesa da Misericórdia da Cidade do Porto. Hospital novo: cartas régias e títulos das compras. Seção D, banco 1, livro n.1. Documentos manuscritos (Arquivo Histórico da Santa Casa de Misericórdia do Porto, Porto). 3 jun. 1768.

DOM JOSÉ.

Carta ao Provedor, Oficiais, e mais Irmãos da Mesa da Misericórdia da Cidade do Porto. Hospital novo: cartas régias e títulos das compras. Seção D, banco 1, livro n.1. Documentos manuscritos (Arquivo Histórico da Santa Casa de Misericórdia do Porto, Porto). 12 jun. 1767.

FORTY, Adrian.

The modern hospital in France and England. In: King, Anthony D. (Ed.). Buildings and society. London: Routledge, Kegan and Paul. 1980.

FOUCAULT, Michel et al.

Les machines à guérir: aux origines de l'hôpital moderne. Bruxelles: Mardaga. 1979.

GONÇALVES, António.

Porto, três milénios de história. S.l.: Publidisa. 2006.

LE GOFF, Jacques.

L'apogée de la France urbaine médiévale. In: Duby, Georges (Dir.). Histoire de la France urbaine 1150-1330. V.2. La ville médiévale. Paris: Seuil, p.189-405. 1980.

OPPERT, Franz.

Hospitals, infirmaries and dispensaries: their construction, interior arrangement and management. London: J. Churchill. 1867.

OSÓRIO, João Mendes.

O Hospital da Santa Casa da Misericórdia do Porto ou proposta apresentada em mesa no dia 2 de Janeiro de 1865 por João Mendes Osório, mesário que então era da mesma santa casa e a contra-proposta apresentada ulteriormente pelo Mordomo das Obras. Porto: Tipografia de António José da Silva Teixeira. 1868.

PROVIDÊNCIA, Paulo. A cabana do higienista. Coimbra: Departamento de Arquitectura da Faculdade de Ciências e Tecnologia da Universidade de Coimbra. 2000.

RICHARDSON, Harriett; GOODALL, Ian (Ed.). English hospitals 1660-1948: a survey of their architecture and design. Swindo: Royal 
Commission on the Historical Monuments of England. 1998.

RODRIGUES, M.M.

Hospital da Misericórdia do Porto (cont.). Occidente, ano 7, v.7, n.212, p.253-254. 11 nov. 1884.

\section{RODRIGUES, M.M.}

Hospital da Misericórdia do Porto. Occidente, ano 7, v.7, n.211, p.243-246. 1 nov. 1884.

SERRANO JR., Adriano.

Hospital Geral de Santo António: apontamentos sobre a sua história. Separata de Boletim do Hospital, v.2, n.3. 1980.

SILVA, Francisco Ribeiro da.

O Porto: das luzes ao liberalismo. Lisboa: Inapa. 2001.

SILVA, Germano.

Porto: sítios com história. Cruz Quebrada: Casa das Letras. 2008.

SILVA, Germano.

Digno da mais bela cidade da Europa. In: Lima, Manuela Abreu e (Coord.). A arte na medicina, Hospital Geral de Santo António. Porto: Árvore, p.11-33. 1998.

SILVA, Helena da.

Soigner à l'hôpital: histoire de la profession infirmière au Portugal (1886-1955). Tese (Doutorado) - Ecole des Hautes Etudes en Sciences Sociales, Paris. Disponível em: http://repositorium.sdum.uminho.pt/ handle/1822/11627. Acesso em: 6 abr. 2012. 2010.

SIMÕES, António Augusto da Costa.

O Hospital de Santo António da Misericórdia do Porto: Relatório. Porto: Tipografia do Jornal do Porto. 1883.

SOARES, Maria Isabel.

António Augusto da Costa Simões (1819-1903): apontamento biográfico. Enfermagem, II (23/24), p.64-69. 2001.
SOUSA, Francisco de Almeida e.

O Hospital Geral de Santo António: história e méritos do Hospital da Cidade. O tripeiro, $7^{\mathrm{a}}$ série, ano 12, n.5, p.130-137. maio 1993.

SOUSA, Francisco de Almeida e.

Os antigos hospitais do Porto. O tripeiro, $7^{\mathrm{a}}$ série, ano 12, n.4, p.98-106. abr. 1993.

STEVENSON, Christine.

Medicine and magnificence: British hospital and asylum architecture 1660-1815. New Haven: Yale University Press. 2000.

TAYLOR, René.

John Carr e o Hospital Geral de Santo António do Porto. Belas artes, 2 ${ }^{\mathrm{a}}$ série, n.15, p.13-31. 1960.

TENON, Jacques René.

Mémoires sur les hôpitaux de Paris. Paris:

Ph.D.Pierres. 1788.

TOLLET, Casimir.

Les hôpitaux modernes au XIXe siècle : description des principaux hôpitaux français et étrangers les plus récemment édifiés, divisés en dix sections par contrées, études comparatives sur leurs principales conditions d'établissement. Paris: Chez l'Auteur. 1894.

TOLLET, Casimir.

Les hôpitaux au XIXe siècle: études, projets, discussions et programmes relatifs à leur construction. L'hôpital civil et militaire de Montpellier. Paris: Chez l'Auteur. 1889.

VIDAL, F. Perry; COSTA, Emídio dos Santos da Rosa e.

Planta da cidade do Porto contendo o palácio de Christal, nova alfândega, e diversos melhoramentos posteriores a 1844. Material cartográfico. Lisboa: Off. de Vasques \& ca . Disponível em: http://purl. pt/3556. Acesso em: 8 ago. 2012. 1865. 